\title{
The Testing of MLAT Method Application by means of Usage low-cost ADS-B Receivers
}

\author{
Stanislav Pleninger \\ Department of Air Transport \\ Czech Technical University in Prague \\ Prague, Czech Republic \\ pleninger@fd.cvut.cz
}

\begin{abstract}
The paper describes the process and results achieved during the measurement which was realized with the aim of identify an applicability of MLAT (Multilateration) method by means of using so-called "low-cost" ADS-B receivers. In terms of measurement, ADS-B receivers without GPS time synchronization module was utilized thus specific time synchronization method was required to implement.
\end{abstract}

Keywords- Surveillance; Mode S; ADS-B; 1090ES; MLAT; Multilateration; transponder

\section{INTRODUCTION}

There is a wide range of so-called "low-cost" ADS-B receivers on today's market that are used for receiving $1090 \mathrm{ES}$ (Extended Squitter) so as to decode and provide a position information obtained from these messages. This approach is suitable for tracking the commercial aircraft which are equipped with ADS-B technology. However, it is not sufficient for tracking the airplanes of General Aviation since only few of them are equipped $1090 \mathrm{ES}$ technology. Nevertheless a majority of these aircraft are equipped by Mode $S$ transponder nowadays. Hence, it is possible to employ a MLAT method in order to survey such traffic. This method enables to determine a position of the aircraft based on a measuring time difference in the signal reception on the several pairs of ground stations. Such kind of systems is already used in the field of commercial aviation. (An example of a producer that supplies alike system may be ERA, a.s.). Nonetheless, such systems are developed for ANSP (Air Navigation Service Providers) so that they are very efficient and expensive as well. Therefore, in terms of affordability, these systems are not applicable to the regional airports, for example.

Nowadays great effort is tend to improve safety in the area of General Aviation. Availability of suitable surveillance system could bring another evolution step in offer services in this area. Whilst the use of the surveillance information is crucial for operating Commercial Aviation nowadays, there is a complete lack of such technology in General Aviation.

The applications of multilateration method using low-cost ADS-B receivers could provide surveillance information for noncritical applications in aviation. It means the applications, whose primarily aren't used for air traffic control, i.e. lives and health of people doesn't depends on such applications. For example it is applications for support of situation awareness of AFIS officers, or applications for FOC (Flight Operation Control) department within airline companies.

Application of MLAT method enables:

- Observation of an airplane based on receiving Mod S replies (Mod A/C replies). I.e. track the airplanes which aren't equipped with ADS-B 1090ES technology.

- Possibility of verification of position information within ADS-B messages. False targets mitigation. There is possible to expect great problems with correctness of information within messages during the implementation 1090 ES technology in GA domain.

- Combination of ADS-B and MLAT method enable more frequent position information updates.

- $\quad$ MLAT method doesn't rely on navigation sensors on board. System is more robustness as far as local GPS jamming is concerned.

\section{The Testing PlatForm}

Within the scope of measurement there were used six ADS-B receivers AURORA from Eurotech Ltd. company. The receivers were lent by CS Soft a.s. company. The ADS-B receiver's deployment which simulated MLAT system is depicted in figure 1.

Since the position of every receiving station must be very precise located, the geodetic GNSS receiver Astech ProMark500 was used for positioning (figure 2). Data were being collected by FastSurvey software, which was operated on pocket PC Ashtech MobileMapper 10. Data were only collected in landscape. Afterwards obtained data were processed by ArcGIS 10.1. software. For positioning in every location around 600 points were measured out by means of GPS eventually GLONASS system. All measurements were improved by the aid of CZEPOS net of permanent references stations. (i.e. DGPS measurement was applied.) 
During the measurement all points in the horizontal plane were positioning in S-JTSK Krrovak coordinate system. Afterwards the transformation into WGS-84 coordination system was performed. The height is specified in the meters after ellipsoid WGS-84 (see Table 1). Actual multilateration calculation was executed in ECEF (Earth Centered Earth Fixed) coordinate system, or more precisely in ENU (EastNorth-Up) local topocentric coordinate system.
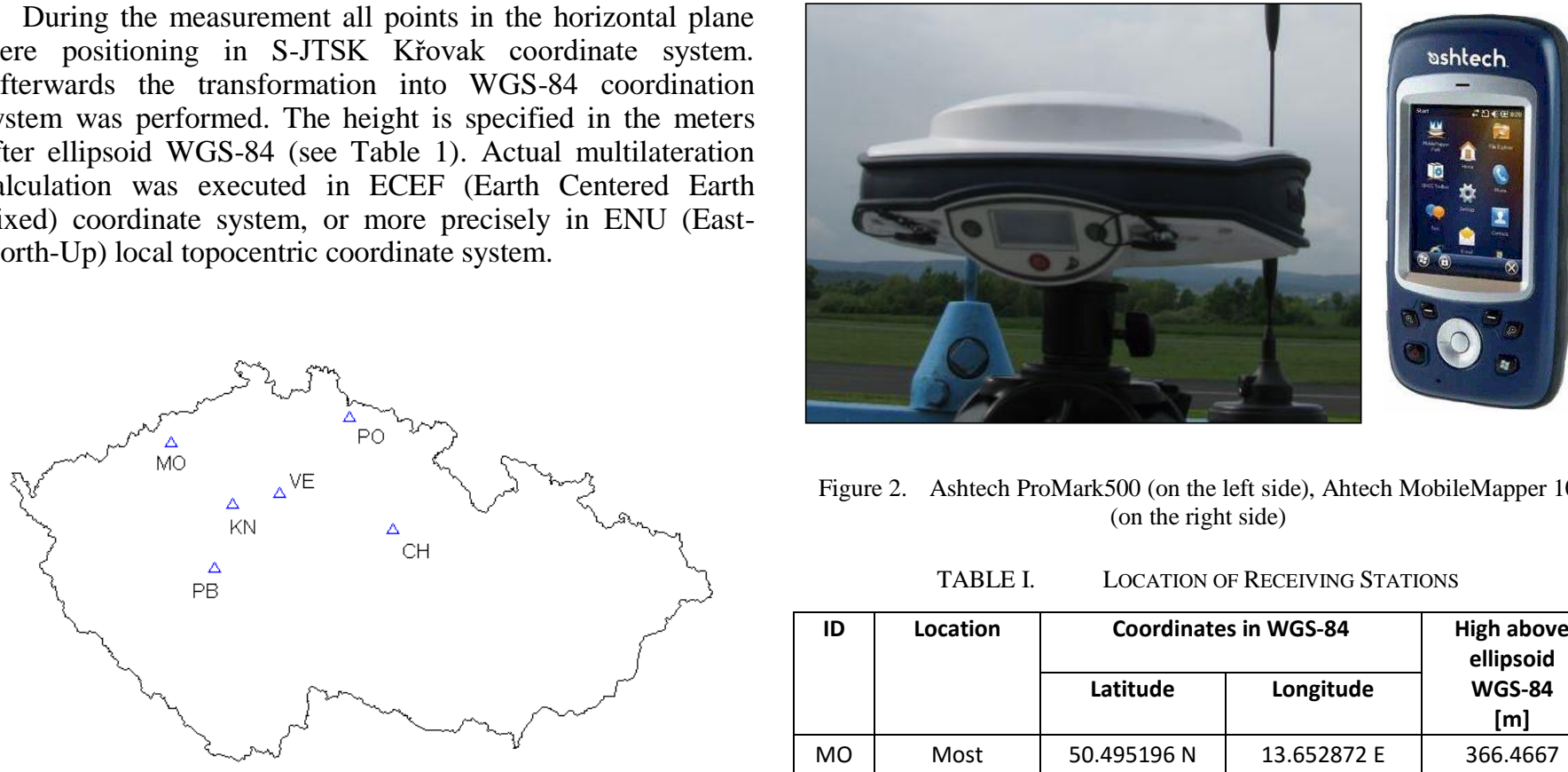

Figure 2. Ashtech ProMark500 (on the left side), Ahtech MobileMapper 10 (on the right side)

TABLE I. LOCATION OF RECEIVING STATIONS

\begin{tabular}{|c|c|c|c|c|}
\hline ID & Location & \multicolumn{2}{|c|}{ Coordinates in WGS-84 } & $\begin{array}{c}\text { High above } \\
\text { ellipsoid } \\
\text { WGS-84 } \\
\text { [m] }\end{array}$ \\
\cline { 3 - 4 } & Latitude & Longitude & 366.4667 \\
\hline MO & Most & $50.495196 \mathrm{~N}$ & $13.652872 \mathrm{E}$ & 463.8876 \\
\hline PB & $\begin{array}{c}\text { Letiště } \\
\text { Př́bram }\end{array}$ & $49.717652 \mathrm{~N}$ & $14.097091 \mathrm{E}$ & 352.5686 \\
\hline KN & Kněževes & $50.117934 \mathrm{~N}$ & $14.258444 \mathrm{E}$ & 183.7791 \\
\hline VE & Nový Vestec & $50.184171 \mathrm{~N}$ & $14.723400 \mathrm{E}$ & 671.9303 \\
\hline PO & $\begin{array}{c}\text { Rozhledna u } \\
\text { Borovice }\end{array}$ & $50.660266 \mathrm{~N}$ & $15.401640 \mathrm{E}$ & 335.2384 \\
\hline $\mathrm{CH}$ & Chrudim & $49.956316 \mathrm{~N}$ & $15.814271 \mathrm{E}$ & \multicolumn{2}{|c}{} \\
\hline
\end{tabular}

TABLE II. ADS-B RECEIVERS LOCATION POSITIONING ERROR

\begin{tabular}{|c|c|c|c|c|c|c|c|c|c|}
\hline \multirow[t]{2}{*}{ Location } & \multirow[t]{2}{*}{$\begin{array}{c}\text { Date of } \\
\text { measurement }\end{array}$} & \multirow{2}{*}{$\begin{array}{c}\text { Average } \\
\text { number of } \\
\text { satellites } \\
\text { used for } \\
\text { measurement }\end{array}$} & \multicolumn{3}{|c|}{ Average value } & \multirow{2}{*}{$\begin{array}{l}\text { Estimation } \\
\text { Horizontal error } \\
\text { (RMS) } \\
\text { [m] }\end{array}$} & \multirow{2}{*}{$\begin{array}{l}\text { Estimation } \\
\text { vertical } \\
\text { error(RMS) } \\
{[\mathrm{m}]}\end{array}$} & \multicolumn{2}{|c|}{$\begin{array}{c}\text { Error ellipse } \\
\text { confidence } \\
\text { intervals }(95 \%)\end{array}$} \\
\hline & & & HDOP & VDOP & PDOP & & & $\begin{array}{c}X \\
{[\mathrm{~m}]}\end{array}$ & $\begin{array}{c}Y \\
{[\mathrm{~m}]}\end{array}$ \\
\hline $\mathrm{KN}$ & 24.5.2013 & 14 & 0.8 & 1.0 & 1.3 & 0.469 & 0.580 & 0.49 & 0.16 \\
\hline VE & 24.5.2013 & 14 & 0.7 & 1.3 & 1.5 & 0,146 & 0.212 & 0.23 & 0.8 \\
\hline $\mathrm{CH}$ & 25.5.2013 & 13 & 0.7 & 1.0 & 1.2 & 0.430 & 0.590 & 0.17 & 0.1 \\
\hline MO & 24.5.2013 & 12 & 0.8 & 1.5 & 1.7 & 0.344 & 0.577 & 0.16 & 0.10 \\
\hline $\mathrm{PO}$ & 25.5.2013 & 13 & 0.7 & 1.0 & 1.2 & 0.357 & 0.470 & 0.25 & 0.04 \\
\hline PB & 24.5.2013 & 14 & 0.8 & 1.0 & 1.3 & 0.183 & 0.178 & 0.24 & 0.7 \\
\hline
\end{tabular}

\section{RECEIVER'S CLOCK TIME SYNCHRONIZATION METHOD}

Necessary assumption for correct system function is achievement of very precise time synchronization (around tens of nanoseconds) of all receiving stations. As was mentioned above AURORA receivers don't dispose of GPS time synchronization module. Due to that reason other method was necessary to be developed and applied in order to enable associate precise timestamps for every received message. Applied method is depicted on figure 3. Method is based on the presumption that at least one aircraft equipped with ADS-B technology is found within the coverage of the system. Thus such aircraft transmits messages containing actual position based on onboard GPS receiver. One of the set of receiving ADS-B station is taken as a reference station (for our example it is $\mathrm{p}_{1}$ station) and its clock represents reference time $t_{1}$. When the aircraft transmit the message containing its position $\mathrm{p}_{\mathrm{A}}$, this message is received both $p_{1}$ and $p_{2}$ receivers in time $t_{1}$ and $t_{2}$ respectively. We know (are able to figure out) distances between $p_{1}$ and $p_{A}$, and between $p_{A}$ and $p_{2}$, which represent the signal propagation trajectory. Thus we can recalculate the message time reception in receiver $\mathrm{p}_{2}$ with respect to $\mathrm{p}_{1}$ 
receiver's clock. Now we have $t_{2}$ (time of message reception at $\mathrm{p}_{2}$ receiver according to $\mathrm{p}_{2}$ clock) and $\mathrm{t}_{2 \text { cor }}$ (time of message reception at $\mathrm{p}_{2}$ receiver according to $\mathrm{p}_{1}$ clock). $\mathrm{t}_{2}-\mathrm{t}_{2}$ cor represents the correction which is consequently applied to each time message reception at $\mathrm{p}_{2}$ receiver.

Unfortunately the value of the correction isn't constant in time but it suffers from some fluctuation which you can see on figure 4 and figure 5. From that reason it is desirable to recalculate the correction as frequently as possible on behalf of keeping the time synchronization as precise as possible.

Of course many other problems arise from above described method. For example there exist very small number of aircraft which report the height above the WGS-84 ellipsoid within the messages nowadays, and thus such height must be estimate from reported barometric height/altitude. It brings into calculation additional errors.

Above described method was applied to all receiving stations, in order to find receiver's clock corrections for our measurement. (As a reference station was set the Kněževes location).

Table III summarizes the errors in time stamps of received messages for particular locations. Two methods are compared in the table III. The first one is a method where for correct time stamps of receiving message the last known time correction is used (i.e. last known correction is added to receiver's clock time stamp). For the second one a correction at the time of reception of a message is calculated based on extrapolation from last $k$ known corrections. The first one method gave so bad results that for our measurement were unusable.

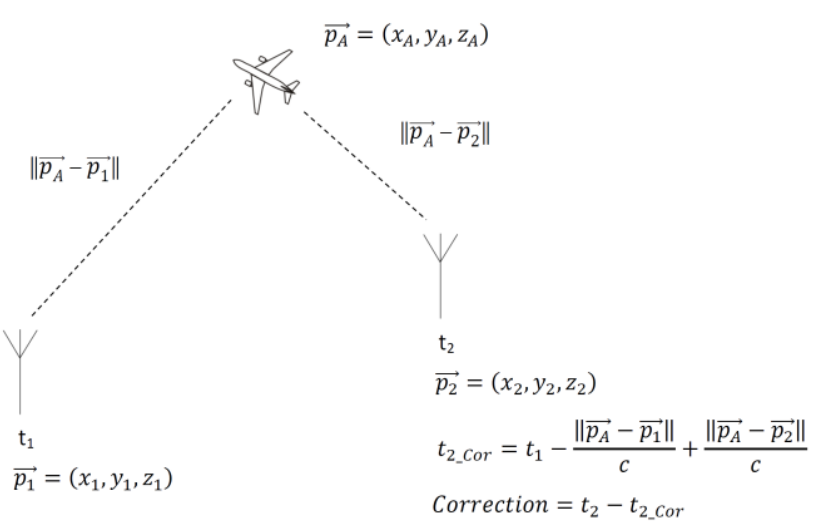

Figure 3. Applied receiver's clock synchronization method

TABLE III. APPLIED CORRECTION ERRORS

\begin{tabular}{|c|c|c|c|c|c|c|}
\hline \multirow{2}{*}{ Location } & \multicolumn{2}{|c|}{ Correction based on N-1 correction } & \multicolumn{2}{c|}{ Correction based on extrapolation from N-k corrections } \\
\cline { 2 - 7 } & $\begin{array}{c}\text { MAE } \\
{[\mathrm{m}]}\end{array}$ & $\begin{array}{c}\text { MSE } \\
{[\mathrm{m}]}\end{array}$ & $\begin{array}{c}\text { RMSE } \\
{[\mathrm{m}]}\end{array}$ & $\begin{array}{c}\text { MAE } \\
{[\mathrm{m}]}\end{array}$ & $\begin{array}{c}\text { MSE } \\
{[\mathrm{m}]}\end{array}$ & $\begin{array}{c}\text { RMSE } \\
{[\mathrm{m}]}\end{array}$ \\
\hline KN & 0 & 0 & 0 & 0 & 0 & 0 \\
\hline VE & $6.878 \mathrm{e}-05$ & $1.342 \mathrm{e}-08$ & $1.158 \mathrm{e}-04$ & $4.822 \mathrm{e}-07$ & $9.583 \mathrm{e}-13$ & $9.789 \mathrm{e}-007$ \\
\hline CH & $2.09 \mathrm{e}-03$ & $1.147 \mathrm{e}-05$ & $3.386 \mathrm{e}-03$ & $3,534 \mathrm{e}-06$ & $8.543 \mathrm{e}-11$ & $9.242 \mathrm{e}-006$ \\
\hline MO & $8.894 \mathrm{e}-06$ & $4.873 \mathrm{e}-10$ & $2.207 \mathrm{e}-05$ & $1.007 \mathrm{e}-06$ & $3.073 \mathrm{e}-12$ & $1.753 \mathrm{e}-006$ \\
\hline PO & $3.137 \mathrm{e}-04$ & $3.382 \mathrm{e}-07$ & $5.815 \mathrm{e}-04$ & $1.978 \mathrm{e}-06$ & $1.403 \mathrm{e}-11$ & $3.746 \mathrm{e}-006$ \\
\hline PB & $1.891 \mathrm{e}-03$ & $8.568 \mathrm{e}-06$ & $2.927 \mathrm{e}-03$ & $2.902 \mathrm{e}-06$ & $6.180 \mathrm{e}-11$ & $7.861 \mathrm{e}-006$ \\
\hline
\end{tabular}

MAE (Mean Absolute Error)

MSE (Mean Square Error)

RMSE (Root Mean Square Error)

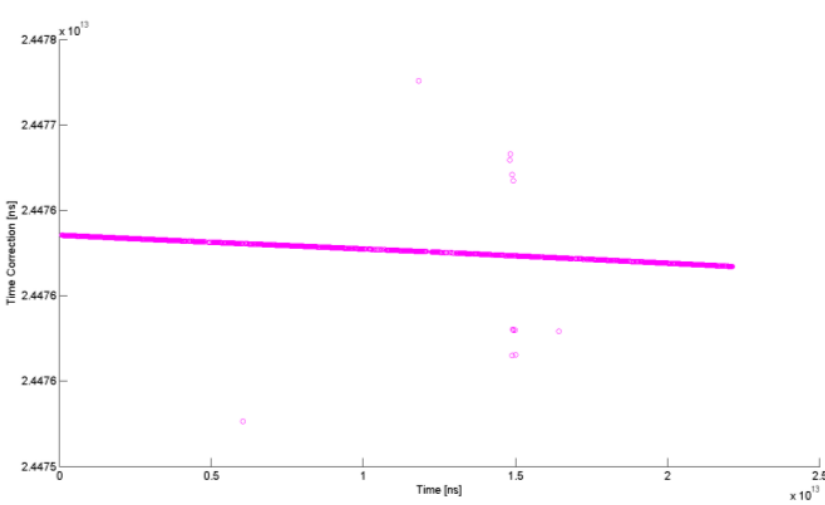

Figure 4. The time drift progression of VE with regard to $\mathrm{KN}$ during $6.13 \mathrm{~h}=1.8228 \mathrm{e}+008 \mathrm{~ns}=0.1823 \mathrm{~s}$

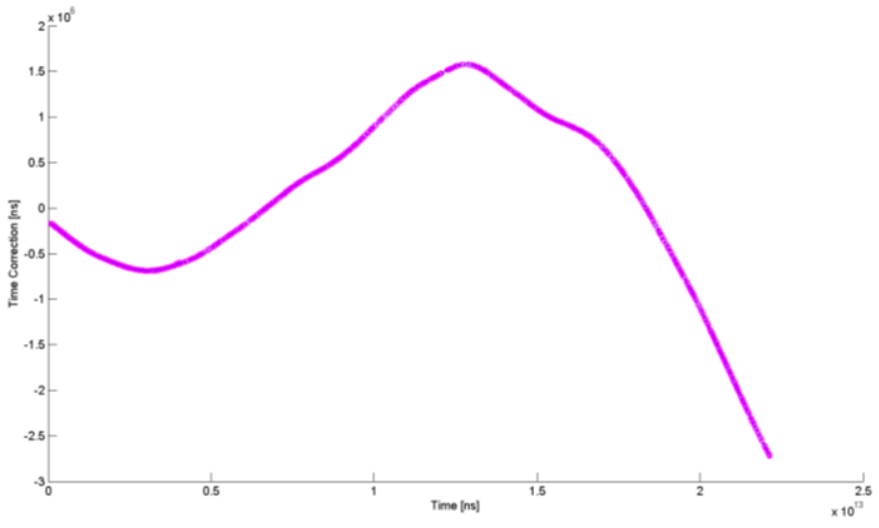

Figure 5. The time drift progression of $\mathrm{VE}$ with regard to $\mathrm{KN}$ - removed linear component from the correction tend 


\section{The Testing MeAsurement}

During the measurement all ADS-B receivers worked in off-line mode and thus multilateration calculation wasn't performed in real time. There were recorded only Mode S messages format DF 17, position extended squitter. Other types of extended squitter messages weren't collected. There were recorded only position squitter messages by the reason of possibility comparison calculated MLAT position with the position announced within ADS-B messages.

TABLE IV. STATISTICS DATA FROM THE MEASUREMENTS

\begin{tabular}{|l|l|l|l|l|}
\hline Location & $\begin{array}{l}\text { Date of } \\
\text { measurement }\end{array}$ & $\begin{array}{l}\text { Length of record } \\
\text { [hour] }\end{array}$ & $\begin{array}{l}\text { Number of received messages } \\
\text { (DF17 position squitter) }\end{array}$ & $\begin{array}{l}\text { Average number of received } \\
\text { messages per second }\end{array}$ \\
\hline KN & 22.7 .2013 & 13.0066753 & 80120 & 1,711 \\
\hline VE & 22.7 .2013 & 6.12558711 & 46967 & 2.13 \\
\hline CH & 22.7 .2013 & 6.0612499318 & 11320 & 0.519 \\
\hline MO & 22.7 .2013 & 7.8025285939 & 52977 & 1.886 \\
\hline PO & 22.7 .2013 & 3.6989794592 & 10765 & 0.808 \\
\hline PB & 22.7 .2013 & 5.8727566112 & 8977 & 0.425 \\
\hline
\end{tabular}

The mathematical description of finding the aircraft position by means of multilateration method represents the Equation 1.

$c \cdot\left(T_{1}-T_{2}\right)=\sqrt{\left(x-x_{1}\right)^{2}+\left(y-y_{1}\right)^{2}+\left(z-z_{1}\right)^{2}}-\sqrt{\left(x-x_{2}\right)^{2}+\left(y-y_{2}\right)^{2}+\left(z-z_{2}\right)^{2}}$

$c \cdot\left(T_{1}-T_{3}\right)=\sqrt{\left(x-x_{1}\right)^{2}+\left(y-y_{1}\right)^{2}+\left(z-z_{1}\right)^{2}}-\sqrt{\left(x-x_{3}\right)^{2}+\left(y-y_{3}\right)^{2}+\left(z-z_{3}\right)^{2}}$

$c \cdot\left(T_{1}-T_{4}\right)=\sqrt{\left(x-x_{1}\right)^{2}+\left(y-y_{1}\right)^{2}+\left(z-z_{1}\right)^{2}}-\sqrt{\left(x-x_{4}\right)^{2}+\left(y-y_{4}\right)^{2}+\left(z-z_{4}\right)^{2}}$

(Eq. 1)

Where:

$\mathrm{x}, \mathrm{y}, \mathrm{z}$ - unknown target (aircraft) position coordinates

$\mathrm{x}_{1}, \mathrm{y}_{1}, \mathrm{z}_{1} \ldots \mathrm{x}_{4}, \mathrm{y}_{4}, \mathrm{z}_{4}$ - receiver stations position coordinates

$\mathrm{T}_{1} \ldots \mathrm{T}_{4}$ - time of message receiving in particular receiving stations.

For $2 \mathrm{D}$ positioning it is necessary to receive the signal at least on three stations. For 3D positioning you must receive the message at least on four stations. Due to the fact that the spectrum is shared among all cooperative surveillance systems without any coordination of transmission causes that the messages might be garbled (overlapped) in a receiver. That results in incorrect message decoding and subsequently to loss of message. Thus it is obvious that the message don't have to be successfully received by the station in spite of a transmitter (airplane) is within the coverage. The probability of a message corruption in general depends on: 1090 RF band saturation, length of message (the longer message the more probability that the message will be garbled) and on a receiver (performance of the system and applied methods for decoding). As far as last point is concerned the low cost ADS-B receivers seem to be very inefficient. Nevertheless this issue will be subjected to an additional research.

The paragraph above explained one of the reasons why we realized measurement only in $2 \mathrm{D}$ despite of the fact that it brings certain decrease in precision because of vertical coordinate had to be estimated only within the calculation. But even so we were able to calculate only 593 plots by MLAT method from recorded data. But on the other hand we must realized that there was used only one type of $1090 \mathrm{ES}$ messages. Other types or formats of Mode $\mathrm{S}$ messages were nonutilisable from the point of view of the precision MLAT measurement analysis. Of course for tracking there would be commonly used all types of received messages by the MLAT system.

Horizontal position error of MLAT measurement was determined according the Eq. 2 and Eq. 3. For every plot position calculated by MLAT system with GPS position reported in the message was compared. Resulting error is presented in graph in fig. 8 .

$$
\begin{gathered}
\text { error }=\sqrt{\Delta x^{2}+\Delta y^{2}} \\
\text { error }=\sqrt{\left(x_{M L A T}-x_{G P S}\right)^{2}+\left(y_{M L A T}-y_{G P S}\right)^{2}}
\end{gathered}
$$

It is necessary to note, that taking the position information transmitted within 1090 ES message as a reference position could be misleading. Due to fact that in Europe isn't any mandate for carriage ADS-B technology nowadays, there exist many aircraft whose transmitting positions information suffer from quite large errors. (It could be caused by incorrect Mode S transponder installation, or the source for position information isn't GPS receiver, or many others.) From that reason there were set the error limit interval $0-20 \mathrm{~km}$ for the statistical analysis. (Resulting error outside this limit was declare as not caused by MLAT system or MLAT measurement.) 


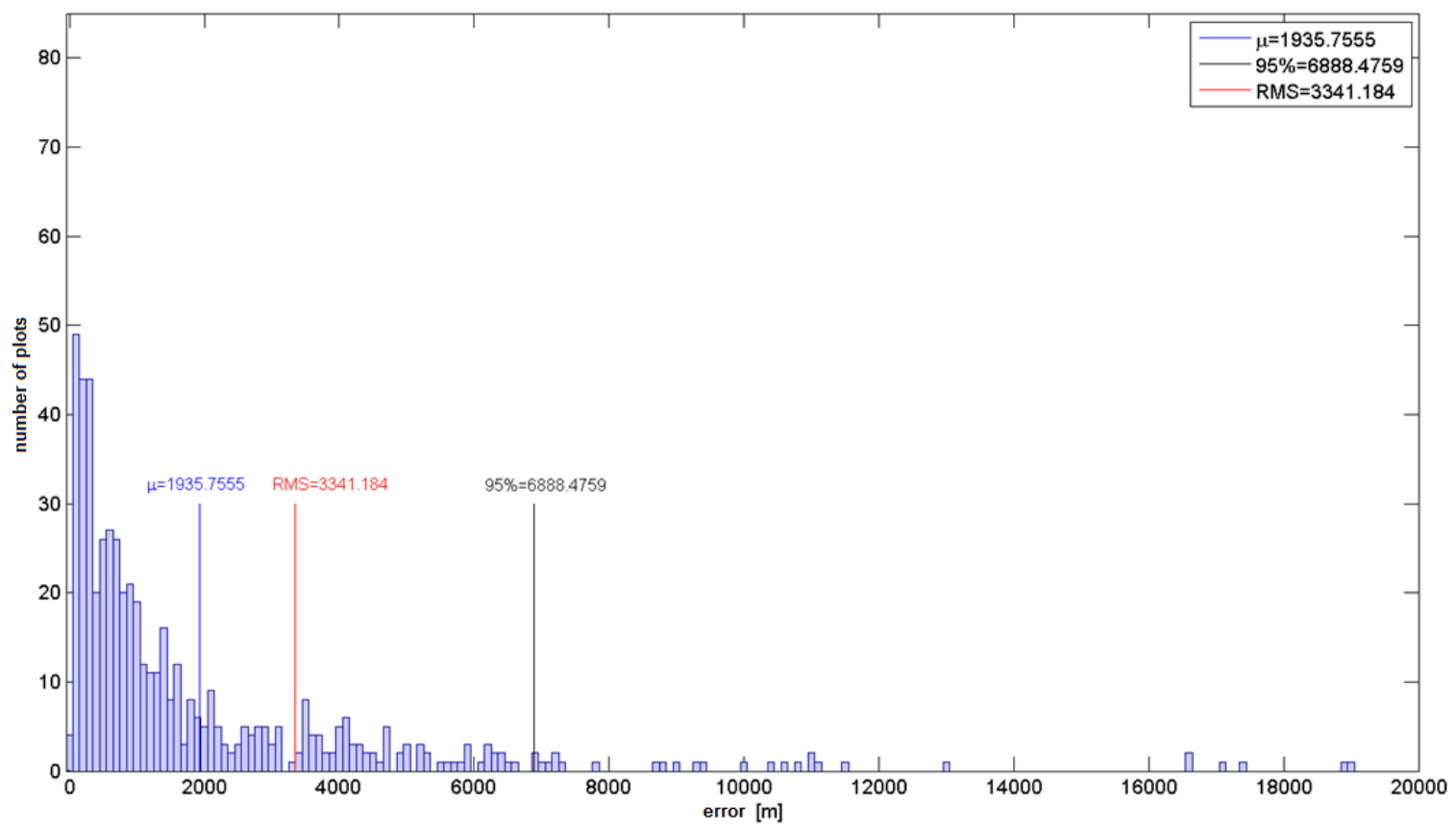

Figure 6. Statistic of targets (aircraft) position measurement error

\section{CONCLUSION}

The aim of this experiment was the primary examination of the feasibility of MLAT measurement based on usage low-cost ADS-B receivers. On the basis of the presented results above, it is possible to say that creation of such systems would be feasible all the more if the receivers with the GPS synchronization module would be used. Such low-cost ADS-B receivers are available today, which give us another benefit. Nevertheless there is still long way in front of us to create fullvalue system that works in real time with parameters suitable for our utilization.

\section{REFERENCES}

[1] ICAO: Annex 10 to the Convention on International Civil Aviation: "Aeronautical Telecommunications", Volume IV: "Surveillance Radar and Collision Avoidance Systems". Amendment no 82.

[2] ICAO, Aeronautical Surveillance Manual (Doc 9924), 1st ed., 2010.

[3] EUROCAE: Technical Specification for Wide Area Multilateration (WAM) Systems, ED-142, 2010.

[4] ICAO: Technical Provision for Mode S Services and Extended Squitter, Doc 9871, Second Edition, 2011.

[5] RTCA: Minimum Operational Performance Standards for $1090 \mathrm{MHz}$ Extended Squitter Automatic Dependent Surveillance-Broadcast (ADS-B) and Traffic Information Services-Broadcast (TIS-B), DO-260B, December 2, 2009. 